\title{
CHROMOBLASTOMYCOSIS: A CASE REPORT FROM BIHAR, INDIA
}

\author{
Anindita Sen1, Gourab Chakraborty2 ${ }^{2}$ Atanu Ray33, Parthajit Banerjee ${ }^{4}$, Nishith Pal ${ }^{5}$
}

${ }_{1}^{1}$ Postgraduate Trainee, Department of Microbiology, MGM Medical College, Kishanganj, Bihar, India.

2 Postgraduate Trainee, Department of Microbiology, MGM Medical College, Kishanganj, Bihar, India.

${ }^{3} H O D$, Department of Microbiology, MGM Medical College, Kishanganj, Bihar, India.

4 Professor, Department of Microbiology, MGM Medical College, Kishanganj, Bihar, India.

${ }_{5}^{5}$ HOD, Department of Microbiology, NRS Medical College, Kolkata, West Bengal, India.

\begin{abstract}
We report a case of chromoblastomycosis in a 42-year-old male, an army personnel by profession. The patient presented with an itchy nodular lesion $(3.5 \times 3 \mathrm{~cm})$ that gradually increased in size over a period of 10 months. Scratching the lesion produced oozing of little fluid. Sclerotic bodies were detected both in KOH mount and histopathological examination. The latter also showed presence of microabscess and irregular epithelial margin. Fonsecaea pedrosoi (Cladosporium type) was isolated by culture as final confirmation.
\end{abstract}

\section{KEYWORDS}

Chromoblastomycosis, Unusual Site, Bihar.

HOW TO CITE THIS ARTICLE: Sen A, Chakraborty G, Ray A, et al. Chromoblastomycosis: A case report from Bihar, India. J. Evolution Med. Dent. Sci. 2016;5(77):5766-5767, DOI: 10.14260/jemds/2016/1300

\section{INTRODUCTION}

Chromoblastomycosis is a chronic fungal infection of the skin and subcutaneous tissue. It is most commonly caused by Fonsecaea pedrosoi, Cladophialophora carrionii and Phialophora verrucosa.(1) The disease is characterised by the presence of sclerotic bodies in the tissue. Although present throughout the world, cases have been predominantly reported from tropical and subtropical countries. In India, several cases have been reported from sub-Himalayan belt. The fungi in the environment are present mostly in the soil. Barefooted agriculturists, labourers and field workers are the most vulnerable population group. The males are most commonly affected.

\section{METHODS}

A 42-year-old male patient, a paramilitary personnel, having no history of trauma, presented with a 10 months' history of an itching nodular lesion over his left forearm (Fig. 1). Initially, it started with a nodule formation and vigorous itching over it. It gradually increased in size to $3.5 \times 3 \mathrm{~cm}$ and started oozing purulent discharge. Patient is non-diabetic and nonhypertensive and has been afebrile during this period. Empirical treatment with topical medication did not show any sign of improvement. General physical examination showed presence of tender lymph node at left axilla. Microscopy of $\mathrm{KOH}$ mount and histopathological examination of tissue sections from the affected site were done. The material was also put to culture in Sabouraud Dextrose Agar and subsequent slide microculture.

Financial or Other, Competing Interest: None.

Submission 19-08-2016, Peer Review 11-09-2016,

Acceptance 19-09-2016, Published 26-09-2016.

Corresponding Author:

Anindita Sen,

AB-51/1, Salt Lake,

Sector-I, Kolkata-700064,

West Bengal,

India.

E-mail: draninditasen@gmail.com

DOI: $10.14260 /$ jemds/2016/1300

\section{(c) (i) $\risingdotseq$}

\section{Ethics}

The procedures followed in this work were in accordance with the ethical standards of the responsible committee on human experimentation.

\section{RESULTS}

Pigmented sclerotic bodies noted in 10\% KOH mount (Fig. 2); histopathological examination showed presence of sclerotic bodies and microabscess (Fig. 3). Culture on Sabouraud Dextrose Agar with chloramphenicol showed fungal colony, and subsequent slide microculture proved the identity to be Fonsecaea pedrosoi (Fig. 4) by the display of characteristic septate hyphae, shield conidia and chains of conidiation. The patient was treated with Itraconazole (200-400 g) daily and Terbinafine (500-1000 g) daily for 6-12 months and showed signs of improvement.

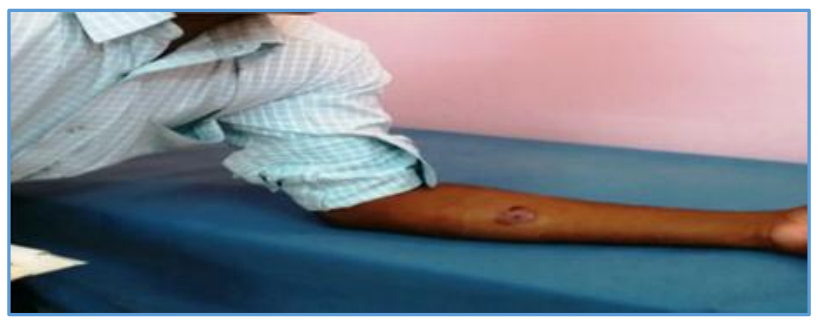

Fig. 1: Showing the Nodular Lesion on the Left Forearm of the Patient.

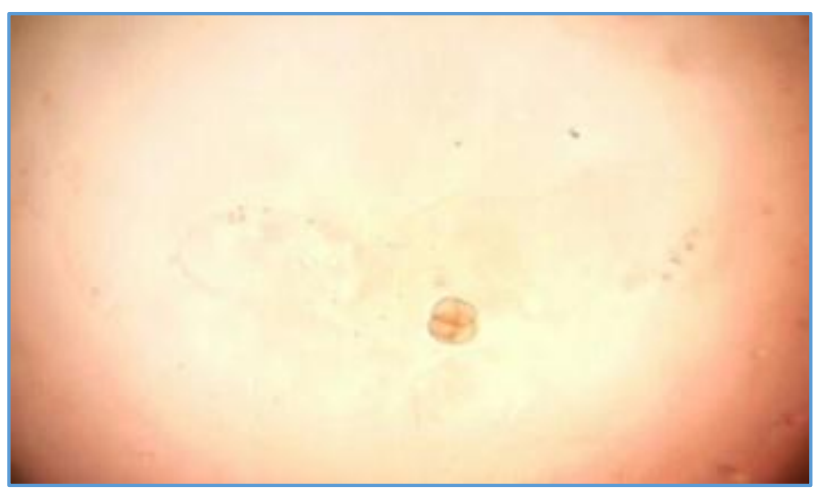

Fig. 2: KOH Finding showing Presence of Sclerotic Body (40x Magnification). 


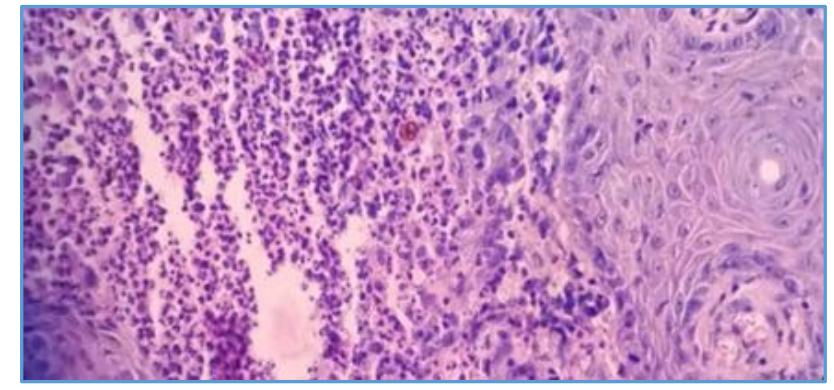

Fig. 3: HPE with H\&E Stain showing Presence of Sclerotic Body and Microabscess (100x Magnification)

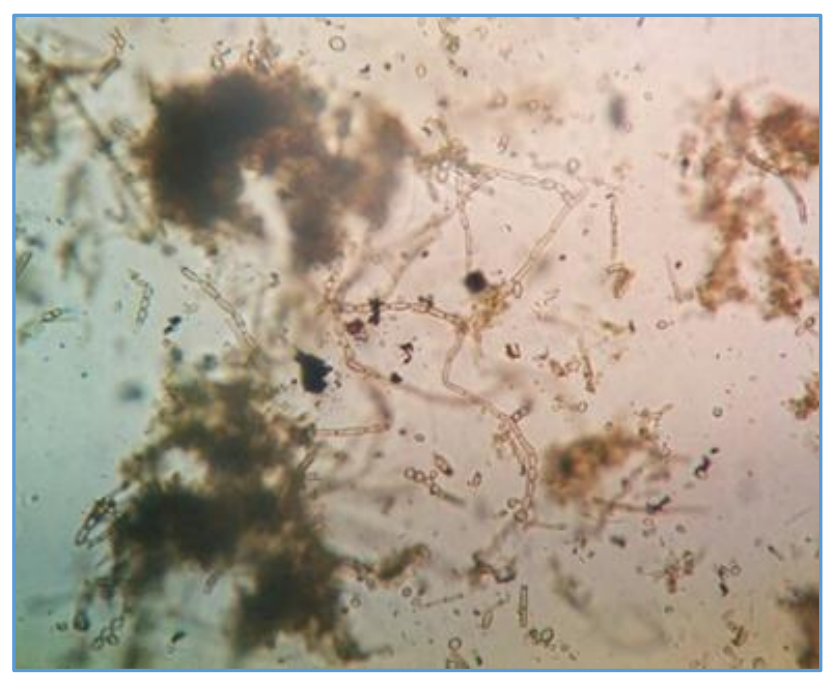

Fig. 4: Slide Culture showing Presence of Septate Hyphae, Shield Conidia and Chains of Conidiation (40x magnification)

\section{DISCUSSION}

Of the two main aetiological agents of chromoblastomycosis, Cladophialophora carrionii is thought to be endemic in semiarid zones while Fonsecaea pedrosoi is seen more in humid tropical climates.(2) The disease occurs predominantly in males (70\%). It has been reported from different parts of the world like Madagascar, Sri Lanka, West Central Africa, Japan and Brazil.(3,4,5,6) After the first report from India by Thomas et al(7) few more cases have been reported including two cases from Bihar in 2014.(8)
The fungus is present from soil, wood, vegetable debris. Chromoblastomycosis usually affects rural workers and usually the lower limbs or foot or hands are the common sites due to traumatic implantation of the fungus. In our case, no such rural background is present. Also the lesion has affected the forearm, which is rather an unusual site. Here lies the clinical importance of this case which might be missed unless the possibility was in mind.

The above-mentioned systemic therapy is the treatment procedure for Chromoblastomycosis. Surgery, cryotherapy and thermotherapy are also advised in combination with chemotherapy.(9) Potassium iodide can also be given for treatment.(10) Good hygiene and adequate nutrition may help the individual abort a potential infection. (2)

\section{REFERENCES}

1. Krzysciak PM, Pindycka-Piaszczynska M, Piaszczynska M. Chromoblastomycosis. Advances in Dermatology and Allergology 2014;31(5):310-21.

2. Kwon-Chung KJ, Bennett TE. Chromoblastomycosis. In: Medical mycology. Pennsylvania: Lea and Febiger 1992; p. 337.

3. Silva JP, de Souza W, Rozental S. Chromoblastomycosis: a retrospective study of 325 cases on Amazonic region Brazil. Mycopathologia 1998;143(3):171-5.

4. Minotto R, Bernardi CD, Mallmann LF, et al. Chromoblastomycosis: a review of 100 cases in the state of Rio Grande do Sul, Brazil. J Am Acad Dermatol 2001;44(4):585-92.

5. Londero AT, Ramos CD. Chromomycosis: a clinical and mycologic study of thirty-five cases observed in the hinterland of Rio Grande do Sul, Brazil. Am J Trop Med Hyg 1976;25(1):132-5.

6. Correia RT, Valente NY, Criado PR, et al. Chromoblastomycosis: study of 27 cases and review of medical literature. An Bras Dermatol 2010;85(4):448-54.

7. Thomas E, Job CK, Hadley GG. Chromoblastomycosis. Indian J Med Sci 1957;11(8):570-3.

8. Kumarjyoti G, Bharati G, Atanu R, et al. Unusual fungus isolated in leg ulcer with swelling. Med PulseInternational Medical Journal 2014;1(2):80-81.

9. Ameen M. Chromoblastomycosis: clinical presentation and management. Clin Exp Dermatol 2009;34(8):849-54.

10. Narendranath S, Sudhakar GK, Pai MR, et al. Safety and efficacy of oral potassium iodide in chromoblastomycosis. Int J Dermatol 2010;49(3):341-3. 